\title{
Overall Well-Being as a Predictor of Health Care, Productivity, and Retention Outcomes in a Large Employer
}

\author{
Lindsay E. Sears, PhD, Yuyan Shi, PhD, Carter R. Coberley, PhD, and James E. Pope, MD
}

\begin{abstract}
Employers struggle with the high cost of health care, lost productivity, and turnover in their workforce. The present study aims to understand the association between overall well-being and these employer outcomes. In a sample of 11,700 employees who took the Well-being Assessment, the authors used multivariate linear and logistic regression to investigate overall well-being as a predictor of health care outcomes (total health care expenditure, emergency room visits, hospitalizations), productivity outcomes (unscheduled absence, short-term disability leave, presenteeism, job performance ratings), and retention outcomes (intention to stay, voluntary turnover, involuntary turnover). Testing this hypothesis both cross-sectionally and longitudinally, the authors investigated the association between baseline well-being and these outcomes in the following year, and the relationship between change in overall well-being and change in these outcomes over 1 year. The results demonstrated that baseline overall well-being was a significant predictor of all outcomes in the following year when holding baseline employee characteristics constant. Change in overall well-being over 1 year also was significantly associated with the change in employer outcomes, with the exception that the relationship to change in manager-rated job performance was marginally significant. The relationships between overall wellbeing and outcomes suggest that implementing a well-being improvement solution could have a significant bottom and top line impact on business performance. (Population Health Management 2013;16:397-405)
\end{abstract}

\section{Introduction}

$\mathbf{H}$ EALTH CARE, LOST PRODUCTIVITY, and turnover pose substantial costs for employers. In 2010, private employers were responsible for approximately $20 \%$ of all health care expenditures in the United States, totaling an estimated $\$ 534.3$ billion. ${ }^{1}$ The estimated cost to employers of absence and performance loss from physical health issues alone is $\$ 225.8$ billion per year, $71 \%$ of which stems from on-the-job productivity impairments. ${ }^{2}$ Employee turnover and replacement costs also impose substantial costs for employers, ${ }^{3}$ which have been estimated to be between $12 \%-40 \%$ of a company's net earnings. ${ }^{4}$

Most of the research to date investigating antecedents of these outcomes has focused on physical health and behavioral risks, though studies from a range of disciplines acknowledge that other elements of overall well-being are influential. Overall well-being is a multidimensional construct that considers a range of important life domains related to work, finances, emotional health, physical health, and behavioral risks, as well as the quality of one's social connections and community. ${ }^{5-7}$ This represents a broader definition of health that accounts for social, psychological, and environmental influences beyond physical health alone. ${ }^{8}$

There is strong evidence that these elements of well-being are associated with a range of human capital costs to employers' outcomes. $^{9-11}$ Figure 1 presents a conceptual model of overall well-being as a predictor of employer outcomes across 3 areas: health care, employee productivity, and retention. Health care outcomes such as medical and pharmacy costs and hospital utilization have been linked to overall well-being in prior studies. ${ }^{12,13}$ Although much of the prior literature on health care outcomes has focused on the physical health and behavioral risk subdomains of overall well-being ${ }^{14,15}$ other well-being subdomains related to work, social relationships, finances, and one's community are associated with chronic and acute illness. ${ }^{16-19}$ Only 1 study has investigated the relationship between overall well-being and health care outcomes longitudinally, finding well-being to be a significant predictor of future health care costs and utilization, controlling for past outcomes. ${ }^{12}$

Productivity, another significant area of lost value for employers, typically is defined as being away from work 


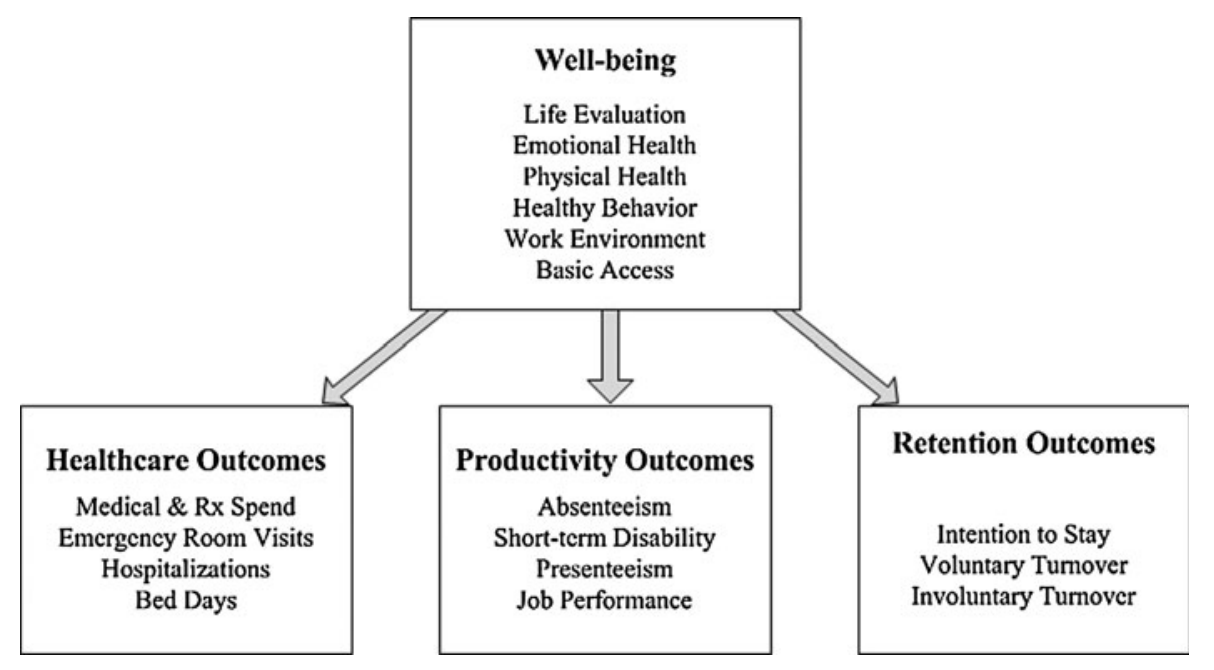

FIG. 1. Model of well-being improvement and employer outcomes. Rx, prescription.

(eg, short-term absenteeism, leave of absence), or not being fully productive in meeting expectations while at work (eg, presenteeism, job performance). Similar to the health care cost literature, most of the research on productivity has focused on the impact of behavioral risk and physical health subdomains of overall well-being. ${ }^{2,10}$ Beyond health issues alone, low overall well-being typically results in low productivity through several processes: a drain in energy, increased distractions while at work, negative emotions about work resulting in withdrawal of effort from one's job, or an inability to attend work or perform well. ${ }^{20-23}$ Few studies have investigated the relationship between overall well-being and productivity, and no studies to date have tested this relationship longitudinally.

Retention outcomes such as intentions to stay with a company and turnover behavior are a third area of costs to employers. These outcomes have been studied primarily in the context of work-related antecedents such as job satisfaction and relationships with managers, ${ }^{25,26}$ though other elements of overall well-being, such as emotional exhaustion and level of embeddedness within the community, are likely to play a role as well. ${ }^{27,28}$ Although limited evidence currently exists, overall well-being is expected to affect levels of employees' commitment to their jobs, psychological withdrawal from work, and the ability to perform well, all of which likely will culminate in resignation from the company (voluntary turnover) or dismissal (involuntary turnover). ${ }^{24}$

To date, only 1 study has examined overall well-being as it relates to employer outcomes across health care, productivity, and retention dimensions. ${ }^{28}$ This research investigated the Individual Well-being Score (IWBS), a multidimensional measure of overall well-being within the Well-being Assessment (WBA), ${ }^{29}$ and found significant cross-sectional relationships with employee health care costs and utilization, selfreported absenteeism, short-term disability, presenteeism, selfrated job performance, and stated intentions to stay with the company. ${ }^{28}$ Evidence for the longitudinal relationship between overall well-being and employer outcomes is still very limited as is research employing objective indicators of productivity and retention. Further examination of overall wellbeing as a predictor of this range of employer outcomes is still needed.

In line with the association between well-being and employer outcomes, studies have found that overall well-being and its subdomains can be improved through individual interventions that target these elements of well-being, ${ }^{30-33}$ and well-being-related interventions have been linked directly to improved employer outcomes such as health care cost and utilization, $^{34-36}$ disability leave, ,7,38 $^{\text {absenteeism, }}{ }^{31,39}$ and presenteeism, ${ }^{40}$ as well as employee turnover intentions. ${ }^{41,42}$ Although it has been established that well-being improvement is attainable through individual intervention, no study to date has examined the connection between overall wellbeing change and outcomes change. Considering that approximately $90 \%$ of employers in the United States offer some kind of health promotion or well-being promotion benefit to their employees, ${ }^{43}$ yet only $7 \%$ offer comprehensive programs, ${ }^{44}$ evidence is needed for employers to justify investment in comprehensive well-being improvement interventions for their workforce.

The present study investigated overall well-being as a predictor of outcomes in a large employer over time, both cross-sectionally and longitudinally. First, the authors examined the extent to which the baseline overall well-being relates to a comprehensive set of employer outcomes in the following year. Second, they tested the extent to which the change in overall well-being is linked to change in the outcomes over 2 time periods. Unlike much of the prior research, most of the employer outcomes examined in this study were collected from objective sources, including health care (total health care spend, emergency room [ER] visits, hospitalizations, hospital bed days), productivity (unscheduled absence, short-term disability leave, presenteeism, job performance ratings), and retention (intention to stay, voluntary turnover, involuntary turnover). These findings have practical implications for intervention design and participant selection, as well as for more generally establishing a business case for an intervention approach that targets overall well-being.

\section{Methods}

\section{Sample}

The participants were from a large Fortune 100 company in the finance and insurance industry. In the summer of 2010, a total of 11,775 employees responded to the baseline WBA (35\% response rate). One year later, 6170 of those employees 
took the follow-up WBA. Excluding 1410 of baseline participants who were no longer employed with the organization in the following year, the follow-up response rate from the baseline sample was approximately $60 \%$. Outcomes data were not available for all employees who took the WBA, and so sample sizes varied depending on the source of the outcome data. Sample sizes for each multivariate regression model are presented in Table 1. Approximately 35\% of respondents were hourly-paid, "nonexempt" employees and were eligible for unscheduled absence analysis.

\section{Setting}

Although this study design was correlational in nature and not designed to test the outcomes of an intervention, several changes to the work environment and programs that were implemented during the study period are noteworthy. During the 12 months between the baseline and follow-up assessment, the organization implemented a comprehensive well-being improvement program. The intervention included components that targeted individuals directly through the WBA and personalized well-being plan, access to a self-directed Web portal offering resources and support, and telephonic coaching for lifestyle and chronic condition management. Other elements of the intervention, such as employee competitions, health education courses, and increased marketing and healthy messaging around the workplace, aimed to improve the workplace culture of well-being.

\section{Measures}

The outcome variables of the present study included health care, productivity, and retention measures. The key predictor was overall well-being measured by the IWBS. Data sources included annual administrations of the WBA, the company's employee engagement survey, health care claims, and human resource administrative data.

Table 1. Sample Sizes of Well-Being ANd Outcomes Regression Models

\begin{tabular}{lcc}
\hline & \multicolumn{2}{c}{ Regression model } \\
\cline { 2 - 3 } & $\begin{array}{c}\text { Baseline WB } \\
\text { predicting } \\
\text { follow-up } \\
\text { outcomes }\end{array}$ & $\begin{array}{c}\text { WB change } \\
\text { predicting } \\
\text { outcomes } \\
\text { change }\end{array}$ \\
Outcomes & & \\
\hline Healthcare & 8917 & 4790 \\
Medical and Rx spend & 8917 & - \\
Any ER visit & 8917 & - \\
Any hospital admission & & \\
Productivity & 3834 & 2127 \\
Unscheduled absences (days) & 10,123 & - \\
Any ST disability & 10,341 & 5563 \\
Job performance rating (1-5) & 6178 & 6173 \\
Presenteeism self-rating (0-100) & & \\
Retention & 7196 & 4372 \\
Intention to stay (0-100) & 11,722 & - \\
Voluntary turnover & 11,722 & - \\
Involuntary turnover & & \\
\hline
\end{tabular}

ER, emergency room; Rx, prescription; ST, short term; WB, wellbeing.
Overall well-being. During the summers of 2010 and 2011, participants completed the WBA, a comprehensive survey containing the Gallup-Healthways Well-being Index, ${ }^{45}$ a health risk assessment, ${ }^{46}$ and validated productivity instruments. ${ }^{47,48}$ The well-being portion of the WBA assesses 6 specific subdomains of well-being: Life Evaluation refers to the cognitive appraisal of one's present and future life situation; Emotional Health captures the daily positive and negative emotions experienced by individuals; Physical Health encompasses both chronic and acute conditions and symptoms affecting employees; Healthy Behavior represents diet, exercise, and smoking habits; Work Environment captures one's satisfaction with a range of elements in the work setting; and Basic Access captures an individual's ability to afford and access the resources needed to be safe and healthy. ${ }^{45}$ Overall well-being was measured by the IWBS, which is computed as the average of these 6 subdomains and ranges on a scale from 0 to $100 .^{29}$

Health care outcomes. Detailed individual-level health care claims and eligibility data provided by health insurance companies were aggregated at the annual level preceding the baseline and follow-up WBAs (August 2009 to July 2010 and August 2010 to July 2011, respectively). Annual medical and pharmacy costs were summed to capture total medical expenditures for individuals. Individuals whose total costs exceeded the $99^{\text {th }}$ percentile at baseline or in the following year were excluded from analysis. A count of annual ER visits and hospital admissions were coded as either 0 for having no utilization or 1 for having at least 1 visit or admission. Change in total claims costs was computed by subtracting total costs in the baseline year from total costs in the follow-up year, such that negative numbers represent a decline in total costs.

Productivity outcomes. Productivity was assessed through objective measures of unscheduled absence, shortterm disability and job performance, and a self-reported measure of presenteeism.

Absenteeism. Unscheduled absence and short-term disability days were tracked over time by the company's human resource system, though unscheduled absence was measured for nonexempt employees only. Like the claims data, total days of absence were summed for each year preceding the WBA fielding. Unscheduled absence was treated as continuous, but for disability absence, individuals were assigned a 0 to represent no disability absence during the 12 months preceding the WBA and 1 to represent any disability absence. Change in unscheduled absence was computed by subtracting total unscheduled absences in the baseline year from total unscheduled absences in the follow-up year.

Presenteeism. Presenteeism, defined as impaired performance at work because of a range of issues or barriers, was measured through the Well-being Assessment for Productivity. ${ }^{47}$ This tool asks employees to report the frequency with which 11 possible issues interfere with work performance on a 3-point scale ("not at all," "some," or "a lot"). These potential issues range from personal issues such as financial stress and physical health problems, to workrelated issues such as lack of resources and issues with 
coworkers. Responses to each of the items are summed and scaled to a total score ranging from 0 to 100 , with 100 representing the highest possible presenteeism ("a lot" response across all 11 items). This instrument has demonstrated acceptable reliability and validity and tracks closely with other validated measures of presenteeism. ${ }^{49}$ Change in presenteeism was calculated by subtracting the baseline presenteeism score from the follow-up presenteeism score.

Job performance. Supervisors were asked to rate each employee's overall job performance at the end of each calendar year on a 5-point scale ranging from "unacceptable" to "exceptional," with higher numbers representing better job performance. Change in job performance was computed by subtracting performance ratings at baseline from performance ratings at follow-up.

Retention. Employee retention was assessed through a self-reported measure of intention to stay as well as archived human resource measures of voluntary and involuntary turnover.

Intention to Stay. In the company's annual employee engagement survey administered in November of each year, employees were asked 3 questions to elicit their intentions to stay with the company. Response options ranged from 1 (strongly disagree) to 5 (strongly agree), and items were recoded, averaged, and scaled to a total score ranging from 0 to 100 , such that higher numbers represent stronger intention to stay with the company. Change in intent to stay was computed by subtracting baseline scores from follow-up scores, such that positive numbers represent an increase in intention to stay.

Voluntary turnover. Between the annual administrations of the WBA, voluntary and involuntary turnover of each employee was tracked through human resource administrative data. Employees were coded as 0 if they were still employed at the time of the second administration of the WBA and 1 if they chose to leave the company during that year.

Involuntary turnover. Like voluntary turnover, employees were coded as 0 if they were still employed at the time of the second administration of the WBA and coded as 1 if they were involuntarily terminated from the company during that year.

\section{Statistical analysis}

Participant data from all sources were merged together at the individual level for analysis. In an effort to describe the change that occurred to the sample over time, means for IWBS and its 6 subdomains were computed for baseline and follow-up participants. Paired-sample $t$ test were conducted to test the differences in these variables within individuals over time to understand the extent to which overall wellbeing changed in this sample.

Prior research has established score ranges to segment IWBS into 5 discrete cohorts based on risk of incurring negative health and performance outcomes. ${ }^{28}$ These segments significantly distinguish employer outcomes cross-sectionally in 2 samples tested previously, so the risk-stratified segments of IWBS at baseline were applied to describe means and standard deviations for outcomes at follow-up. Multivariate regressions were employed to statistically assess the relationships between baseline IWBS and follow-up business outcomes controlling for age, sex, marital/partnership status, and education. Specifically, multiple linear regression models were used for linear outcomes including total health care costs, unscheduled absences, job performance ratings, presenteeism, and intention to stay. Logistic regression analysis was used for dichotomous outcomes including having any ER visit, any hospital admission, any short-term disability, voluntary turnover, and involuntary turnover.

The longitudinal relationships of well-being change as a predictor of change in outcomes also were examined. Both voluntary and involuntary turnover outcomes indicated individuals who were no longer employed at the time of follow-up, and so investigating well-being change for these variables was not possible. Because of the rarity of the health care utilization and short-term disability outcome variables, only changes in the continuous outcomes in the study (health care costs, unscheduled absence, supervisor-rated job performance, presenteeism, and intention to stay) were examined. The means and standard deviations for change in outcomes were described according to their change in IWBS segments (well-being segment decreased at least 1 segment, stayed in the same segment, or increased at least 1 well-being segment). Multiple linear regression models were conducted in order to statistically test the effect of well-being change on change in the continuous outcomes. Baseline age, sex, marital/partnership status, and education also were controlled for in the equations.

\section{Results}

To describe the extent to which the sample changed over the study period, mean change in overall well-being and its subdomains are displayed in Figure 2. A series of paired $t$ tests indicated that overall well-being and each of the subdomains changed significantly in a positive direction over time $(P<0.01)$, with the greatest change occurring in the healthy behavior domain.

\section{Predicting follow-up outcomes}

The average follow-up outcomes according to overall well-being segment at baseline are presented in Table 2 . With regard to health care outcomes, employees whose well-being was in the low segment at baseline incurred $\$ 857.54$ more in medical and pharmacy costs in the following year than those in the high well-being segment. Similarly, the rate of future ER visits and hospital admissions for the group starting in the low well-being segment was double that of their high well-being counterparts. The productivity outcomes at follow-up exhibited a similar trend across well-being segments from baseline. On average, those who started in the low wellbeing segment at baseline had approximately 2 more days of annual unscheduled absence and more than double the likelihood of short-term disability, reported over 3 times the level of presenteeism, and were rated almost half a point lower on performance on a 5-point scale by their supervisors as compared to those in the high well-being segment at baseline. Average retention outcomes also improved in relation to the level overall well-being at baseline. On average, 
FIG. 2. Overall well-being and domain change for employees receiving a comprehensive well-being improvement intervention over 1 year. A series of paired-sample $t$ tests revealed that overall well-being and domain improvement were statistically significant $(P<0.01)$.

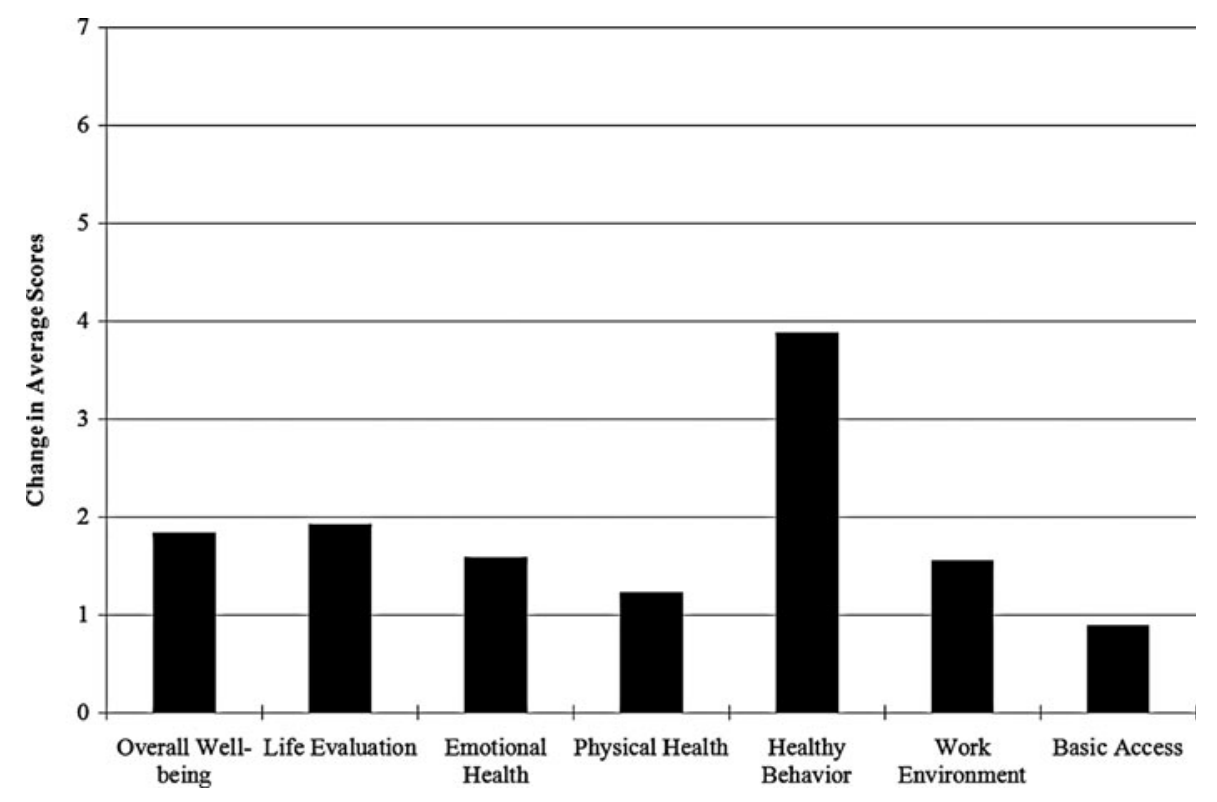

intentions to stay with the company were highest for those who started in the high well-being segment in the prior year. Moreover, employees who were in the high well-being segment at baseline had 30\% fewer voluntary departures from the company and 3 times fewer involuntary departures than employees who started in the low well-being segment. Across most outcome variables, the variance in outcomes is greatest in lower levels of well-being.
Multivariate regression results linking baseline IWBS to outcomes at follow-up, controlling for employee characteristics at baseline, are presented in Table 3. IWBS was a significant predictor such that higher overall well-being scores at baseline were associated with lower health care costs and utilization at follow-up. Relationships were also statistically significant for the productivity outcomes. Holding employee characteristics constant, higher well-being at baseline was

Table 2. Descriptive Outcome Means at Follow-up According to Individual Well-being Score SEgments at BASELine

\begin{tabular}{|c|c|c|c|c|c|}
\hline \multirow[b]{2}{*}{ Follow-up outcome mean (SD) } & \multicolumn{5}{|c|}{ Baseline IWBS segment } \\
\hline & Lo & Lo-Mid & Mid & $\mathrm{Mid}-\mathrm{Hi}$ & $\mathrm{Hi}$ \\
\hline \multicolumn{6}{|l|}{ Health care } \\
\hline Medical and Rx spend & $\begin{array}{c}\$ 2,038.78 \\
(\$ 4,344.21)\end{array}$ & $\begin{array}{c}\$ 1,507.39 \\
(\$ 3,369.41)\end{array}$ & $\begin{array}{c}\$ 1,383.12 \\
(\$ 3,124.94)\end{array}$ & $\begin{array}{c}\$ 1,273.89 \\
(\$ 3,091.73)\end{array}$ & $\begin{array}{c}\$ 1,181.24 \\
(\$ 2,752.85)\end{array}$ \\
\hline Any ER visit & $\begin{array}{l}9 \% \\
(3 \%)\end{array}$ & $\begin{array}{l}7 \% \\
(3 \%)\end{array}$ & $\begin{array}{l}5 \% \\
(2 \%)\end{array}$ & $\begin{array}{l}5 \% \\
(2 \%)\end{array}$ & $\begin{array}{c}4 \% \\
(2 \%)\end{array}$ \\
\hline Any hospital admission & $\begin{array}{l}4 \% \\
(2 \%)\end{array}$ & $\begin{array}{l}2 \% \\
(1 \%)\end{array}$ & $\begin{array}{l}2 \% \\
(2 \%)\end{array}$ & $\begin{array}{l}2 \% \\
(2 \%)\end{array}$ & $\begin{array}{l}2 \% \\
(1 \%)\end{array}$ \\
\hline \multicolumn{6}{|l|}{ Productivity } \\
\hline Unscheduled absences (days) & $\begin{array}{l}3.96 \\
(6.15)\end{array}$ & $\begin{array}{c}3.25 \\
(5.32)\end{array}$ & $\begin{array}{c}2.46 \\
(4.35)\end{array}$ & $\begin{array}{c}1.88 \\
(3.52)\end{array}$ & $\begin{array}{c}1.79 \\
(3.21)\end{array}$ \\
\hline Any ST disability & $\begin{array}{l}15 \% \\
(36 \%)\end{array}$ & $\begin{array}{c}9 \% \\
(28 \%)\end{array}$ & $\begin{array}{c}7 \% \\
(26 \%)\end{array}$ & $\begin{array}{c}5 \% \\
(23 \%)\end{array}$ & $\begin{array}{c}6 \% \\
(23 \%)\end{array}$ \\
\hline Job performance rating $(1-5)$ & $\begin{array}{c}3.11 \\
(1.52)\end{array}$ & $\begin{array}{c}3.31 \\
(1.26)\end{array}$ & $\begin{array}{c}3.42 \\
(1.18)\end{array}$ & $\begin{array}{c}3.5 \\
(1.02)\end{array}$ & $\begin{array}{l}3.58 \\
(.94)\end{array}$ \\
\hline Presenteeism self-rating (0-100) & $\begin{array}{c}32.75 \\
(16.86)\end{array}$ & $\begin{array}{c}23.09 \\
(14.90)\end{array}$ & $\begin{array}{c}18.35 \\
(13.54)\end{array}$ & $\begin{array}{c}13.76 \\
(11.39)\end{array}$ & $\begin{array}{c}9.81 \\
(9.90)\end{array}$ \\
\hline \multicolumn{6}{|l|}{ Retention } \\
\hline Intention to stay $(0-100)$ & $\begin{array}{c}65.08 \\
(37.35)\end{array}$ & $\begin{array}{c}71.64 \\
(35.59)\end{array}$ & $\begin{array}{c}75.48 \\
(33.64)\end{array}$ & $\begin{array}{c}78.96 \\
(31.51)\end{array}$ & $\begin{array}{c}83.39 \\
(28.65)\end{array}$ \\
\hline Voluntary turnover & $\begin{array}{l}10 \% \\
(30 \%)\end{array}$ & $\begin{array}{c}8 \% \\
(27 \%)\end{array}$ & $\begin{array}{c}7 \% \\
(26 \%)\end{array}$ & $\begin{array}{c}6 \% \\
(24 \%)\end{array}$ & $\begin{array}{c}7 \% \\
(25 \%)\end{array}$ \\
\hline Involuntary turnover & $\begin{array}{c}6 \% \\
(23 \%)\end{array}$ & $\begin{array}{c}4 \% \\
(19 \%)\end{array}$ & $\begin{array}{c}3 \% \\
(18 \%)\end{array}$ & $\begin{array}{c}2 \% \\
(14 \%)\end{array}$ & $\begin{array}{c}2 \% \\
(12 \%)\end{array}$ \\
\hline
\end{tabular}

ER, emergency room; IWBS, Individual Well-being Score; Rx, prescription; ST, short term. 
Table 3. Multivariate and Logistic Regression Results of Baseline Well-being as a Predictor of Follow-up Outcomes

\begin{tabular}{|c|c|c|c|}
\hline \multirow[b]{2}{*}{ Follow-up outcomes } & \multicolumn{3}{|c|}{ IWBS predictor } \\
\hline & $\beta$ & $S E$ & Standardized $\beta$ \\
\hline \multicolumn{4}{|l|}{ Health care } \\
\hline Medical and Rx spend & -16.34 & 2.436 & $-0.07^{* *}$ \\
\hline Any ER visit ${ }^{\mathrm{a}}$ & -0.02 & 0.003 & $-0.13^{* *}$ \\
\hline Any hospital admission ${ }^{\mathrm{a}}$ & -0.01 & 0.005 & $-0.08^{*}$ \\
\hline \multicolumn{4}{|l|}{ Productivity } \\
\hline Unscheduled absences (days) & -0.05 & 0.005 & $-0.16^{* *}$ \\
\hline Any ST disability ${ }^{\mathrm{a}}$ & -0.03 & 0.003 & $-0.19^{* *}$ \\
\hline Job performance rating $(1-5)$ & 0.01 & 0.001 & $0.14^{* *}$ \\
\hline $\begin{array}{l}\text { Presenteeism self-rating } \\
\quad(0-100)\end{array}$ & -0.45 & 0.012 & $-0.44^{* *}$ \\
\hline \multicolumn{4}{|l|}{ Retention } \\
\hline Intention to stay $(0-100)$ & 0.35 & 0.029 & $0.14^{* *}$ \\
\hline Voluntary turnover ${ }^{a}$ & -0.01 & 0.003 & $-0.05^{* *}$ \\
\hline Involuntary turnover ${ }^{a}$ & -0.03 & 0.004 & $-0.20^{* *}$ \\
\hline
\end{tabular}

${ }^{\text {a}}$ Logistic regression analysis. All models controlled for age, sex, education, and marital/partnership status.

${ }^{*} P<0.05,{ }^{* *} P<0.01$.

ER, emergency room; IWBS, Individual Well-being Score; Rx, prescription; ST, short term.

associated with higher productivity outcomes at follow-up. With respect to the retention outcomes, having a higher wellbeing score at baseline was significantly predictive of likelihood of retention in the following year.

\section{Predicting change in outcomes}

Descriptive change among the continuous outcomes according to change across IWBS segments is presented in Table 4 . For instance, the average change in total health care costs for employees whose well-being decreased at least 1 segment was $\$ 318.30$ higher than the change in total annual costs for those whose well-being increased at least 1 segment. In contrast to the cross-sectional descriptive table, which suggests that the outcome variance is greatest in the lower well-being segment, variance of outcomes is more evenly distributed across levels of well-being segment change.

Regression results in which overall well-being change was examined as a predictor of change in outcomes are presented in Table 5. Well-being change was a statistically significant predictor of change in health care costs such that those whose overall well-being score improved exhibited a greater reduction in costs. Well-being change also was a significant predictor of change in most productivity and retention outcomes but was only marginally predictive of change in supervisor ratings of job performance.

\section{Discussion}

The present study aims to understand the relationship between overall well-being and employer outcomes both cross-sectionally and longitudinally. In a large sample of employees, it was found that overall well-being was predictive of future employer outcomes related to health care (total health care spend, ER visits, hospitalizations), productivity (unscheduled absence, short-term disability leave, presenteeism, job performance ratings), and retention (intention to stay, voluntary turnover, involuntary turnover). These findings go beyond the current literature that has narrowly defined, measured, and investigated employee health and health-related interventions according to behavioral health risks and chronic illness. Also, while selfreported information is a valuable source of outcomes data, the outcomes analyzed in this study were primarily from objective data obtained from the employer. This addresses concerns about potential self-reporting bias skewing relationships between predictors and outcome data coming from a single source.

Overall well-being was found to be a significant leading predictor across 3 types of employer outcomes. First, the significant relationships between overall well-being and follow-up health care costs and utilization confirm previous work that found well-being as a leading indicator of health care outcomes. ${ }^{12}$ This finding is particularly noteworthy given the high amount of variance in the distribution of claims

Table 4. Descriptive Mean Change in Outcomes According to Change in Individual Well-Being Score Segments

\begin{tabular}{|c|c|c|c|}
\hline \multirow[b]{2}{*}{ Change in outcomes Mean (SD) } & \multicolumn{3}{|c|}{ Change across IWBS segment } \\
\hline & Decreased $1+$ IWBS segment & Stayed in same IWBS segment & Increased $1+$ IWBS segment \\
\hline \multicolumn{4}{|l|}{ Health care } \\
\hline Medical and Rx spend & $\begin{array}{c}\$ 123.25 \\
(\$ 3496.37)\end{array}$ & $\begin{array}{c}-\$ 48.36 \\
(\$ 3393.86)\end{array}$ & $\begin{array}{c}-\$ 195.05 \\
(\$ 3682.29)\end{array}$ \\
\hline \multicolumn{4}{|l|}{ Productivity } \\
\hline Unscheduled absences (days) & $\begin{array}{c}0.53 \\
(3.32)\end{array}$ & $\begin{array}{c}0.30 \\
(2.94)\end{array}$ & $\begin{array}{l}-0.06 \\
(2.90)\end{array}$ \\
\hline Job performance rating $(1-5)$ & $\begin{array}{l}0.18 \\
(.93)\end{array}$ & $\begin{array}{l}0.15 \\
(.91)\end{array}$ & $\begin{array}{l}0.19 \\
(.88)\end{array}$ \\
\hline Presenteeism self-rating (0-100) & $\begin{array}{c}5.66 \\
(13.33)\end{array}$ & $\begin{array}{c}0.53 \\
(11.23)\end{array}$ & $\begin{array}{c}-4.51 \\
(12.86)\end{array}$ \\
\hline \multicolumn{4}{|l|}{ Retention } \\
\hline Intention to stay $(0-100)$ & $\begin{array}{c}11.18 \\
(46.11)\end{array}$ & $\begin{array}{c}12.00 \\
(44.13)\end{array}$ & $\begin{array}{c}13.80 \\
(43.92)\end{array}$ \\
\hline
\end{tabular}

IWBS, Individual Well-being Score; Rx, prescription. 
Table 5. Multivariate Regression Results of Well-being Change as a Predictor of Change IN Outcomes

\begin{tabular}{lccc}
\hline & \multicolumn{3}{c}{ IWBS change predictor } \\
\cline { 2 - 4 } Change in outcomes & $\beta$ & SE & Standardized $\beta$ \\
\hline $\begin{array}{l}\text { Health care } \\
\quad \text { Medical and Rx spend }\end{array}$ & -12.77 & 4.40 & $-0.04^{* *}$ \\
$\begin{array}{l}\text { Productivity } \\
\text { Unscheduled absences } \\
\quad \text { (days) }\end{array}$ & -0.02 & 0.01 & $-0.06^{* *}$ \\
$\quad \begin{array}{l}\text { Job performance rating (1-5) } \\
\text { Presenteeism self-rating } \\
\quad(0-100)\end{array}$ & 0.002 & 0.001 & $0.025^{\psi}$ \\
$\begin{array}{l}\text { Retention } \\
\text { Intention to stay (0-100) }\end{array}$ & 0.40 & 0.01 & $-0.36^{* *}$ \\
\hline
\end{tabular}

All models controlled for age, sex, education and marital/ partnership status.

$\psi P<0.10,{ }^{*} P<0.05,{ }^{* *} P<0.01$.

IWBS, Individual Well-being Score; Rx, prescription.

costs, making the statistical testing of such a relationship more stringent. Second, this study extended existing research linking health risk and illness to productivity outcomes to show that a comprehensive indicator of overall well-being at baseline significantly predicts follow-up absenteeism, presenteeism, and job performance ratings. Lastly, this study raised awareness around employee retention as an additional source of costs to employers that often has been overlooked in the health risk literature. There were significant associations between overall well-being at baseline and subsequent measures of employee retention both in terms of subjective reports of intentions to stay with the company and in terms of voluntary and involuntary turnover behavior. This lends support to the idea that employees with low wellbeing are more likely to leave the company, either through willful withdrawal or involuntary dismissal processes.

Changes in well-being over 1 year were associated with changes in employer outcomes over that same time period, accounting for baseline employee characteristics. On average, employees whose well-being improved exhibited reduced health care costs, fewer unscheduled absences, reduced presenteeism, and increased intentions to stay. Wellbeing change, however, was not a significant predictor of changes to supervisor-rated job performance. This could be related to the accuracy with which supervisor ratings reflect the true performance of an employee. Studies have identified substantial error inherent to rater judgments that can be influenced by individual rater bias, rater training, and policies or practices influencing the validity of ratings, such as forced distribution rating systems. ${ }^{49,50}$ It is also possible that employees will strive to meet their supervisors' expectations, potentially at the detriment of their own overall well-being. Instead, well-being may influence other dimensions of job performance, such as the quality of work or services delivered, or the decision to go "above and beyond," engaging in discretionary behaviors that help coworkers and the company be more successful. ${ }^{51}$ Future research should investigate these dimensions of job performance and examine other sources of job performance data.
The current findings have meaningful implications for employers in terms of building a business case for well-being as an organizational performance strategy. Although significant improvement in well-being was observed in this sample of employees who were exposed to a comprehensive well-being improvement intervention, this study was not designed in such a way to infer a causal relationship between the intervention and outcomes improvement. Nevertheless, well-being improvement was found to be significantly related to positive changes in most employer outcomes. Coupling this new knowledge with outcomes from a previously conducted randomized controlled trial finding that overall well-being can be improved through a well-being intervention, ${ }^{32}$ the results in the present study imply that employers who adopt a well-being improvement strategy for their business may stand to realize substantial savings through the improved health, performance, and retention of their workers.

The present study also establishes the validity and potential usefulness of the IWBS as an informative tool for program design and implementation, as well as a legitimate business metric. Given its association with outcomes of value to employers, IWBS has several potential applications with respect to designing and implementing programs that address overall well-being. It may be used to select at-risk individuals for intervention outreach, determine intervention intensity, and inform the content of personalized interventions by leveraging the detailed subdomain data within wellbeing. Regarding the use of overall well-being as a business metric, it has been established through this and prior research that the IWBS is indicative of current and future business performance outcomes. ${ }^{28}$ As opposed to collecting, aggregating, and tracking data from health insurance plans, short-term disability service providers, and administrative databases, the present findings support the use of IWBS as a current and leading indicator of a range of business performance metrics. Such a single comprehensive measure provides the information necessary to assess the collection of changes often implemented by employers from year to year.

This research has several potential limitations that should be addressed in future studies. Because these results were based on a sample of employees working for the same employer, the authors are unable to determine the extent to which the relationships between well-being and outcomes might generalize to different organizations, industries, and sectors. Moreover, as is the case with most every employersponsored well-being improvement initiatives, there is potential for selection bias given that the participation in the WBA was voluntary. With respect to outcome measures, a range of objective criteria were included that manifest as costs to the employer; however, the measure of presenteeism was based on employee self-perceptions and the measure of job performance was based on supervisor perceptions and the company's rating system. Both self-report and more objective data sources have the potential to contain error and may yield different results with respect to how they relate to well-being improvement. There is a need for future research to assess on-the-job performance and presenteeism outcomes using methods and measures that are less prone to error. Lastly, because of the nonexperimental nature of this study design, causality cannot be inferred with respect to the relationship between overall well-being change and change in 
employer outcomes. Further investigation in this area is warranted.

\section{Conclusion}

The present study provides evidence that overall wellbeing is predictive of future employer outcomes related to health care, productivity, and retention. The study also demonstrated that well-being change over time is linked to changes in all employer outcomes tested but one, which was marginally significant. These findings support the interrelated nature of employee health, wellness, benefits, and external policies that create the environment of human performance. They also demonstrate that employers may realize substantial health care savings, productivity gains, and turnover reduction by improving the well-being of their employees.

\section{Disclosure Statement}

This study was funded by Healthways, Inc. Drs. Sears, Shi, Coberley, and Pope were employed by or stakeholders of Healthways, Inc., the funder of this study, when the work was conducted.

\section{References}

1. The Henry J. Kaiser Family Foundation. Health care costs: A primer. Available at: http://www.kff.org/insurance/7670 .cfm. Accessed August 26, 2012.

2. Stewart WF, Ricci JA, Chee E, Morganstein D. Lost productive work time costs from health conditions in the United States: Results from the American Productivity Audit. J Occup Environ Med 2003;45:1234-1246.

3. Griffeth RW, Hom PW, Gaertner S. A meta-analysis of antecedents and correlates of employee turnover: Update, moderator tests, and research implications for the next millennium. J Manag 2000;26:463-488.

4. PriceWaterhouseCoopers. Driving the bottom line: Improving retention. Available at: http://www.pwc.com/ en_US/us/hr-saratoga/assets/saratoga-improving-retention .pdf. Accessed August 13, 2012.

5. Rath T, Harter JK. Wellbeing: The Five Essential Elements. New York: Gallup Press; 2010.

6. Diener E. Guidelines for national indicators of subjective well-being and ill-being. Appl Res Qual Life 2006;1:151-157.

7. Diener E. Subjective well-being: The science of happiness and a proposal for a national index. Am Psychol 2000;55:34.

8. World Health Organization. Constitution of the World Health Organization. Basic documents, forty-fifth edition, supplement, October 2006. Available at: http://www.who .int/governance/eb/who_constitution_en.pdf. Accessed January 2, 2013.

9. Lynch WD, Gilfillan LA, Jennett C, Bender J. Health risks and health insurance claims costs: Results for health hazard appraisal responders and nonresponders. J Occup Environ Med 1993;35:28-33.

10. Boles M, Pelletier B, Lynch W. The relationship between health risks and work productivity. J Occup Environ Med 2004;46:737-745.

11. Kemery ER, Mossholder KW, Bedeian AG. Role stress, physical symptomatology, and turnover intentions: A causal analysis of three alternative specifications. Available at: http://bus.lsu.edu/management/faculty/abedeian/articles/ RSPhySym-JOB1987.pdf. Accessed August 26, 2012.
12. Harrison PL, Pope JE, Coberley CR, Rula EY. Evaluation of the relationship between individual well-being and future health care utilization and cost. Popul Health Manag 2012;15:325-330.

13. Shi Y, Sears LE, Coberley CR, Pope JE. Classification of individual well-being scores for the determination of adverse health and productivity outcomes in employee populations. Popul Health Manag Epub ahead of print 26 September 2012.

14. Thompson D, Brown JB, Nichols GA, Elmer PJ, Oster G. Body mass index and future healthcare costs: A retrospective cohort study. Obesity 2001;9:210-218.

15. Bauer MS, Kirk GF, Gavin C, Williford WO. Determinants of functional outcome and healthcare costs in bipolar disorder: A high-intensity follow-up study. J Affect Disorders 2001;65: 231-241.

16. Silva A. Where you live matters to your health. Virtual Mentor 2006;8:766-770.

17. Van der Doef M, Maes S. The job demand-control (-support) model and physical health outcomes: A review of the strain and buffer hypotheses. Psychol Health 1998;13:909-936.

18. Uchino BN, Cacioppo JT, Kiecolt-Glaser JK. The relationship between social support and physiological processes: A review with emphasis on underlying mechanisms and implications for health. Psychol Bull 1996;119:488.

19. Skinner MA, Zautra AJ, Reich JW. Financial stress predictors and the emotional and physical health of chronic pain patients. Cognitive Ther Res 2004;28:695-713.

20. Schaufeli WB, Bakker AB, Van Rhenen W. How changes in job demands and resources predict burnout, work engagement, and sickness absenteeism. J Organ Behav 2009;30:893-917.

21. Schaufeli WB, Bakker AB. Job demands, job resources, and their relationship with burnout and engagement: A multisample study. J Organ Behav 2004;25:293-315.

22. Kim J, Garman ET. Financial stress, pay satisfaction and workplace performance. Compensation Benefits Rev 2004; 36:69-76.

23. Hanisch KA, Hulin CL. Job attitudes and organizational withdrawal: An examination of retirement and other voluntary withdrawal behaviors. J Vocat Behav 1990;37:60-78.

24. Barrick MR, Mount MK, Strauss JP. Antecedents of involuntary turnover due to a reduction in force. Pers Psychol 1994;47:515-535.

25. Harris KJ, Kacmar KM, Witt LA. An examination of the curvilinear relationship between leader-member exchange and intent to turnover. J Organ Behav 2005;26:363-378.

26. Tett RP, Meyer JP. Job satisfaction, organizational commitment, turnover intention, and turnover: Path analyses based on meta-analytic findings. Pers Psychol 1993;46:259-293.

27. Wright TA, Cropanzano R. Emotional exhaustion as a predictor of job performance and voluntary turnover. J Appl Psychol 1998;83:486.

28. Lee TW, Mitchell TR, Sablynski CJ, Burton JP, Holtom BC. The effects of job embeddedness on organizational citizenship, job performance, volitional absences, and voluntary turnover. Acad Manage J 2004;47:711-722.

29. Evers KE, Prochaska JO, Castle PH, et al. Development of an individual well-being scores assessment. Available at: http:// www.psywb.com/content/2/1/2. Accessed January 2, 2013.

30. Hutchinson AD, Wilson C. Improving nutrition and physical activity in the workplace: A meta-analysis of intervention studies. Health Promot Int 2012;27:238-249.

31. Parks KM, Steelman LA. Organizational wellness programs: A meta-analysis. J Occup Health Psych 2008;13:58. 
32. Prochaska JO, Evers KE, Castle PH, et al. Enhancing multiple domains of well-being by decreasing multiple health risk behaviors: A randomized clinical trial. Popul Health Manag 2012;15:276-286.

33. Martin A, Sanderson K, Cocker F. Meta-analysis of the effects of health promotion intervention in the workplace on depression and anxiety symptoms. Scand J Work Environ Health 2009;35:7-18.

34. Lorig KR, Sobel DS, Stewart AL, et al. Evidence suggesting that a chronic disease self-management program can improve health status while reducing hospitalization: A randomized trial. Med Care 1999;37:5.

35. Johnston B, Wheeler L, Deuser J, Sousa KH. Outcomes of the Kaiser Permanente tele-home health research project. Arch Fam Med 2000;9:40.

36. Bly JL, Jones RC, Richardson JE. Impact of worksite health promotion on health care costs and utilization. JAMA 1986; 256:3235-3240.

37. Wolf AM, Siadaty MS, Crowther JQ, et al. Impact of lifestyle intervention on lost productivity and disability: Improving control with activity and nutrition. J Occup Environ Med 2009;51:139-145.

38. Bertera RL. The effects of workplace health promotion on absenteeism and employment costs in a large industrial population. Am J Public Health 1990;80:1101-1105.

39. Anderzén I, Arnetz BB. The impact of a prospective surveybased workplace intervention program on employee health, biologic stress markers, and organizational productivity. J Occup Environ Med 2005;47:671.

40. Cancelliere C, Cassidy JD, Ammendolia C, Côté P. Are workplace health promotion programs effective at improving presenteeism in workers? A systematic review and best evidence synthesis of the literature. BMC Public Health 2011;11:395.

41. Proudfoot JG, Corr PJ, Guest DE, Dunn G. Cognitivebehavioural training to change attributional style improves employee well-being, job satisfaction, productivity, and turnover. Pers Indiv Differ 2009;46:147-153.

42. Moen P, Kelly EL, Hill R. Does enhancing work-time control and flexibility reduce turnover? A naturally occurring experiment. Soc Probl 2011;58:69.
43. US Department of Health and Human Services. $1999 \mathrm{Na}$ tional Worksite Health Promotion Activities: Summary Report. Washington, DC: US Department of Health and Human Services; 2000.

44. Linnan L. Using results from the 2004 National Worksite Health Promotion Survey to identify areas for improving the health of employees at the workplace. Available at: https:// apha.confex.com/apha/135am/techprogram/paper_154594 .htm. Accessed August 13, 2012.

45. Gallup, Healthways. Gallup-Healthways Well-Being Index: Methodology Report for Indexes. Available at: http://wellbeingindex.com / files / Gallup-Healthways $\% 20$ Index $\% 20$ Methodology\%20Report\%20FINAL\%203-25-08.pdf. Accessed February 20, 2012.

46. Edington DW. Emerging research: A view from one research center. Sci Health Promot 2001;15:341-349.

47. Prochaska JO, Evers KE, Johnson JL, et al. The well-being assessment for productivity. J Occup Environ Med 2011; 53:735-742.

48. Kessler RC, Barber C, Beck A, et al. The World Health Organization Health and Work Performance Questionnaire (HPQ). J Occup Environ Med 2003;45:156-174.

49. Hoyt WT. Rater bias in psychological research: When is it a problem and what can we do about it? Psychol Methods 2000;5:64.

50. Bretz RD, Milkovich GT, Read W. The current state of performance appraisal research and practice: Concerns, directions, and implications. J Manage 1992;18:321-352.

51. Cropanzano R, Rupp DE, Byrne ZS. The relationship of emotional exhaustion to work attitudes, job performance, and organizational citizenship behaviors. J Appl Psychol 2003;88:160.

Address correspondence to: Lindsay E. Sears, PhD Healthways, Inc. Center for Health Research 701 Cool Springs Boulevard Franklin, TN 37067

E-mail: Lindsay.Sears@healthways.com 